\title{
Biomechanical Response of Head During Impact Loading
}

\author{
O. Fanta*, P. Kubový, K. Jelen \\ Department of Anatomy and Biomechanics, Faculty of Physical Education and Sport, Charles University, \\ Prague, Czech Republic \\ *Corresponding author:fantao@seznam.cz
}

DOI: $10.2478 / \mathrm{v} 10158-010-0011-3$

\begin{abstract}
The biomechanical response of the head during impact loading represents a globally highlighted issue associated mainly with passive vehicle safety.

Based on the detection of the dynamic values and biomaterial characteristics during the head impact loading are we able to observe the biomechanical response of biological structures to the loading. The internal mechanical response to the speed vector spreading in both extra- and subdural areas is discussed and its dependency on the characteristics of external mechanical loading. Mathematical and physical models were used for the computational tasks of inverse dynamics that allow the solving of interactional biomechanical conditions in both real and extrapolated extreme-loading situations. Based on the changes of input mechanical loading, i.e., the changes of static, dynamic, impulse and inertial loading, the appropriate biomechanical reaction was able to be determined and the value of the HIC (Head Injury Criterion) specified which can be approximately correlated to the AIS (Abbreviated Injury Scaled) using a table.

The knowledge gathered can be applied to all situations when a head hits an obstacle. The mechanisms relate well to the "injury" issues during both work and free time activities, such as transportation, sports, etc.
\end{abstract}

KEY WORDS: Biomechanics, head injury, impact, passive safety, head injury criterion.

\section{INTRODUCTION}

Head injuries are the most frequent threat to life. It is caused mostly by the strong impact of the head with some sort of obstacle. Looking at this issue from the point of view of most frequent brain injuries we can find that the foremost reason is traffic accidents $(60-80 \%)$, including motorbike riders $(10 \%)$ and pedestrians/bicycle riders (8-10\%). The second most common reason is falls $(10 \%)$. Approximately $9 \%$ of brain traumas are caused by assaults, sports, and shooting injuries. Less than $8 \%$ of cranial traumas come from industrial work, especially metallurgy, mining, construction, wood-processing, etc. (Juráň, et al., 2001).

From the very beginning biomechanics has been concerned with mechanical damage to the human body. The majority of attention has been centered on traffic and sports injuries. There have been many efforts to prevent such accidents. Primarily these efforts have focused on the most frequent causes of more severe head, chest and spine injuries. A mathematicalphysical elastic-dynamical model has been devised based on the known facts which has allowed the observation of the head injury mechanism, i.e., during the impact. The model has 
11 degrees of freedom and includes a skull, brain, spine, upper and lower limbs, and a torso fastened to a frame. We have further examined the behavior of the scalp, brain and velamen, both in humans and apes, and simulated it using the Maxwel-Kelvin model. The measurement was performed using implanted accelerometers and pressure meters on a human and ape head, and the results have been summarized in a system simulation by the means of a linear impedance model with two degrees of freedom. The area of injuries of the spine and its components was observed using a model consisting of three-component elements and thus simulating the whole spine. This simulation was further extended by the mechanical influences of the spinal flexors and extensors.

From the biomechanical point of view the human body can be conceived of as a closed mass system which can be simulated by a movable spatial system of objects. The structure consists of individual subsystems representing the body segments. After mastering a given motion situation the systems as the whole begin an interaction with their surroundings (Sychra, 1993)

External mechanical stress applied to a head can be divided in this manner:

1) Contact (i.e., the impact of the object with the head), further subdivided into:

- Penetrating - the impacting object penetrates through the skull, usually causing impressive and compound fractures and other brain injuries - these are relatively rare during car accidents recently.

- Non-penetrating - there is no penetration of objects or skull shards in the skull interior:

- by static force - generates high tension, eventually deformation,

- $\quad$ by dynamic force - in a very short time period (20-200 ms),

- $\quad$ impulse injury - generates a shock wave, spreading further

through the brain tissue (Kovanda, et al., 2000).

The type of external mechanical stress is decided from the size of an object's contact area and also from the speed of the impact. Apart from fractures, there may be also contusions caused by contact mechanism. Usually these are located at the spot of impact, but can also be found at the opposite spot, according to the so-called par contre-coup mechanism.

2) Contactless, inertial - is caused by acceleration and deceleration, e.g., during the movement of the cervical spine (the origin of the so-called inertial injuries) (Juráň, et al., 2001).

External mechanical stress causes the internal mechanical response of various anatomical parts of the head. If the external stress exceeds the so-called injury tolerance level, defined for the body or its parts as the limit of the specified injury occurrance (Ommaya, et al., 1994), an internal mechanical response occurs. Various parts of the head may be affected by a wide scale of injury mechanisms.

The most frequent is a traumatic brain injury. The key to understanding the external stress which causes the injury is the internal mechanical response of the brain. This comes from an external mechanical impact, transported from the head's skin to the brain threads via the skull. An inner mechanical response is affected by the strength and duration of the external mechanical impact. The strength has to be large enough for the injury-causing tension to affect the brain threads. In other words, some degree of tolerance has to be exceeded. The duration determines the manner and scale of the internal brain tension.

Short impacts can be defined as impacts which have a characteristic duration equal to the characteristic time of the head system's own frequency. These impacts happen, 
for example, when shot (a bullet of small weight) hits a head with high speed. This particular case is also called a ballistic impact. An inner mechanical brain response is subsequently determined by the progression of generated waves. This means that a wave front, containing high or increasing tension, progresses through the brain tissue. This progression of the tension wave through the brain tissue has been considered to be important for the internal mechanical response for a long time and there are circumstances specified (Brands, 2002) under which the wave progression responsible for the internal mechanical response is given.

If a head is hit with a heavy object with a lower speed, an impact with longer duration occurs, and no wave front progression can be detected. Additionally, the response usually has a lower gradient. In slower impact conditions a quasi-static response occurs, during which the inertial effect can be omitted (Brands, 2002).

Two types of waves have been specified, spreading through the brain, based on the analytic use of linear viscous-elastic theory (Brands, 2002):

1) S-waves (shear waves) generated during longer duration impacts (e.g., car accidentrelated impacts) with a frequency between 25 and $300 \mathrm{~Hz}$.

2) P-waves (compression waves) generated during short duration impacts like a ballistic impact. In this case the waves spreading through the brain have a frequency between $10 \mathrm{kHz}$ and $3 \mathrm{MHz}$.

\section{PROCESS LEADING TO HEAD INJURY}

During physiological or extreme loading a series of events occurs, depending on the manner of the force, which implies the final biomechanical response of the organism (Figure 1). The great variability of the types of external mechanical loading prevents a simple description and simulation of a biomechanical reaction and internal mechanical response, which fundamentally affects the injury mechanism, on a physical model. The influence of the variability of the mechanical properties of soft and rigid tissues, as well as the influence of frequency and impulse loading of individual structures, plays a major role in determining an adequate biomechanical response (Brands, 2002).

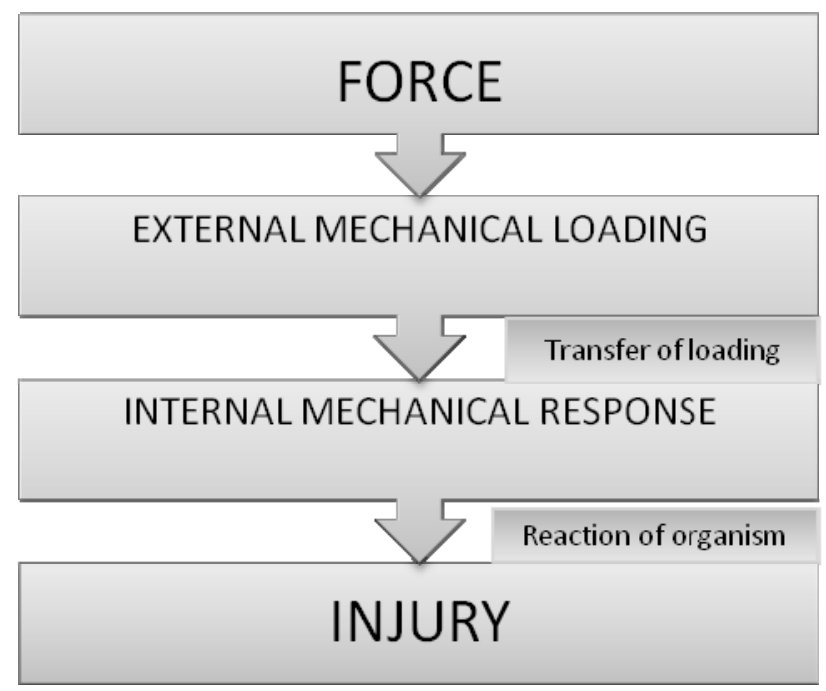

Figure 1: Process leading to head injury. 
Taking this into consideration, it is crucial to specify individual internal mechanical responses based on external mechanical loading by testing physical models.

A biomechanical response is, in this case, represented especially by the speed and acceleration of individual head segments and tissue structures. These act as the source of the majority of biomechanical injury criteria, i.e., Head Injury Criterion, further along by the pressure distribution and the speed of the specific wave spreading, as well as its other properties (frequency, wave length). Head Injury Criterion (HIC) is defined as:

$$
H I C=\left\{\left(t_{2}-t_{1}\right)\left(\frac{1}{t_{2}-t_{1}} \int_{t_{2}}^{t_{2}} a(t) d t\right)^{2 \cdot 6}\right\}_{\max }
$$

where:

$\boldsymbol{a}(\boldsymbol{t})$ is the resulting value of head acceleration and $\boldsymbol{t}_{1}$ and $\boldsymbol{t}_{\mathbf{2}}$ are the variable start and end times of the interval, in which the HIC reaches its maximum.

For the reason of regulation the maximum of $t_{1}$ a $t_{2}$ interval is set to 15 or $36 \mathrm{~ms}$. For the consequences of frontal impact the HIC has been presented as a reasonable discriminator between serious and less serious injuries (Tarriere, 1981). It also correlates with a risk of skull fracture (Ran, et al., 1984).

By testing and choosing an appropriate process of biomechanical response identification the reference values of biomechanical indicators are determined, based on measurements under standard physiological loading, and this data is correlated with values under extreme loading. At present there is no precise method specified for the detection of biomechanical indicators. Additionally, the threshold of organism tolerance to impact loading or head vibrations differs greatly among authors.

\section{EXPERIMENT}

The goal of the experiment was to simulate various characteristic external mechanical loading in laboratory conditions. This loading is represented by individual detectable internal mechanical responses. Based on the results of this experiment it is possible to evaluate a biomechanical response to extreme loading with greater precision and to better characterize the injury criterion and injuries possibly incurred.

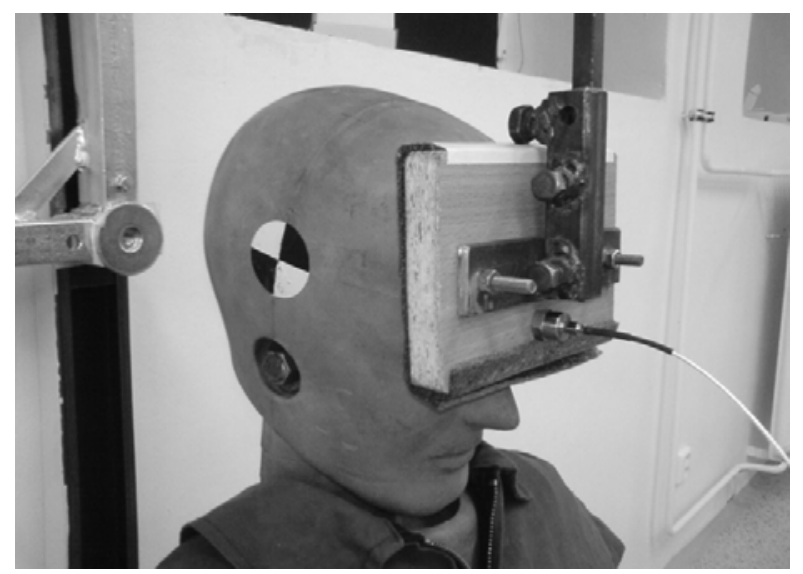

The main detection method consists of scanning biomechanical reactions to external mechanical loading. Such a purpose is served by an impactor with the capability of force 
and impact rigidity regulation, which has been constructed in the BEZ laboratory at FTVS UK. Measuring took place on probands as well as a figurine ÚSMD Manikin, used by the Transportation faculty of C VUT in Prague for compound impact tests, the so-called crash-tests. The impact blanket was equipped with a $2 \mathrm{~mm}$ thick dampening foam for slowing the impact and also with an accelerometer for determining the primal impact. The tested person was seated on a regular school chair without a head support. The chair was secured against moving. The impact spot was the middle of os frontale at a slight forward bend. A three axis accelerometer was placed at the center of gravity of the figurine's head and a modified hat with one axis accelerometers was placed on the proband's head. Conditions were the same for the figurine and the probands. The mass of the weight and the impactor displacement were counted from the required values of the HIC before the actual experiment. To secure the displacement the impactor was fixed using fish line.

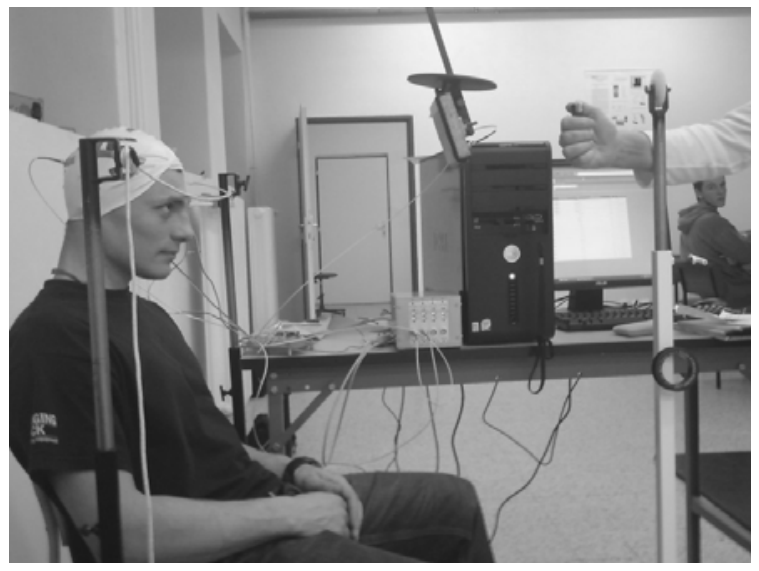

After over firing the fish line the gravitation force caused a motion and the predicted impact. All the data from the accelerometers were recorded by a computer and subsequently analyzed and correlated, and the output values verified. Thus the biomechanical response of a "living" head and a figurine head to an impact could be simultaneously compared.

6 measurements were performed (marked 001-006) for both probands and a figurine, using weights and displacements as seen in Figure 2. For clarification the results for the figurine are marked " $\mathrm{D}$ ", for the first proband "O", and for the second proband " $\mathrm{P}$ ".

Table 1:Weight and displacement.

\begin{tabular}{|l|r|r|r|r|r|r|}
\hline \multicolumn{1}{|c|}{ Number of impact } & \multicolumn{1}{c|}{ 001 } & \multicolumn{1}{c|}{ 002 } & \multicolumn{1}{c|}{ 003 } & \multicolumn{1}{c|}{ 004 } & \multicolumn{1}{c|}{005} & \multicolumn{1}{c|}{006} \\
\hline Weight (N) & 5 & 5 & 5 & 10 & 10 & 10 \\
\hline Displacement (m) & 0,47 & 0,77 & 0,97 & 0,47 & 0,77 & 0,97 \\
\hline
\end{tabular}

\section{RESULTS}

At the moment of impact with the head the impactor's speed sharply decreases, deceleration increases, the dampening foam is compressed, and the impactor transfers its energy, via the specific contact areas, to the head. Soft tissues are compressed and the skull is deformed. The head gains a large acceleration with approx. $2 \mathrm{~ms}$ delay, which propagates dorsally. The motion is unevenly accelerated. After approx. 6ms the impactor's deceleration reaches its highest value and begins to decrease and stop. The acceleration of the head continues for 3 more milliseconds and at a particular moment that depends on the rigidity and strength of the impact, regarding violence timespan, it stops and starts to decrease. The oscillation 
is then strongly inhibited due to the neck muscles and also the properties of viscous-elastic materials complex of the skull and brain (Figure 2).

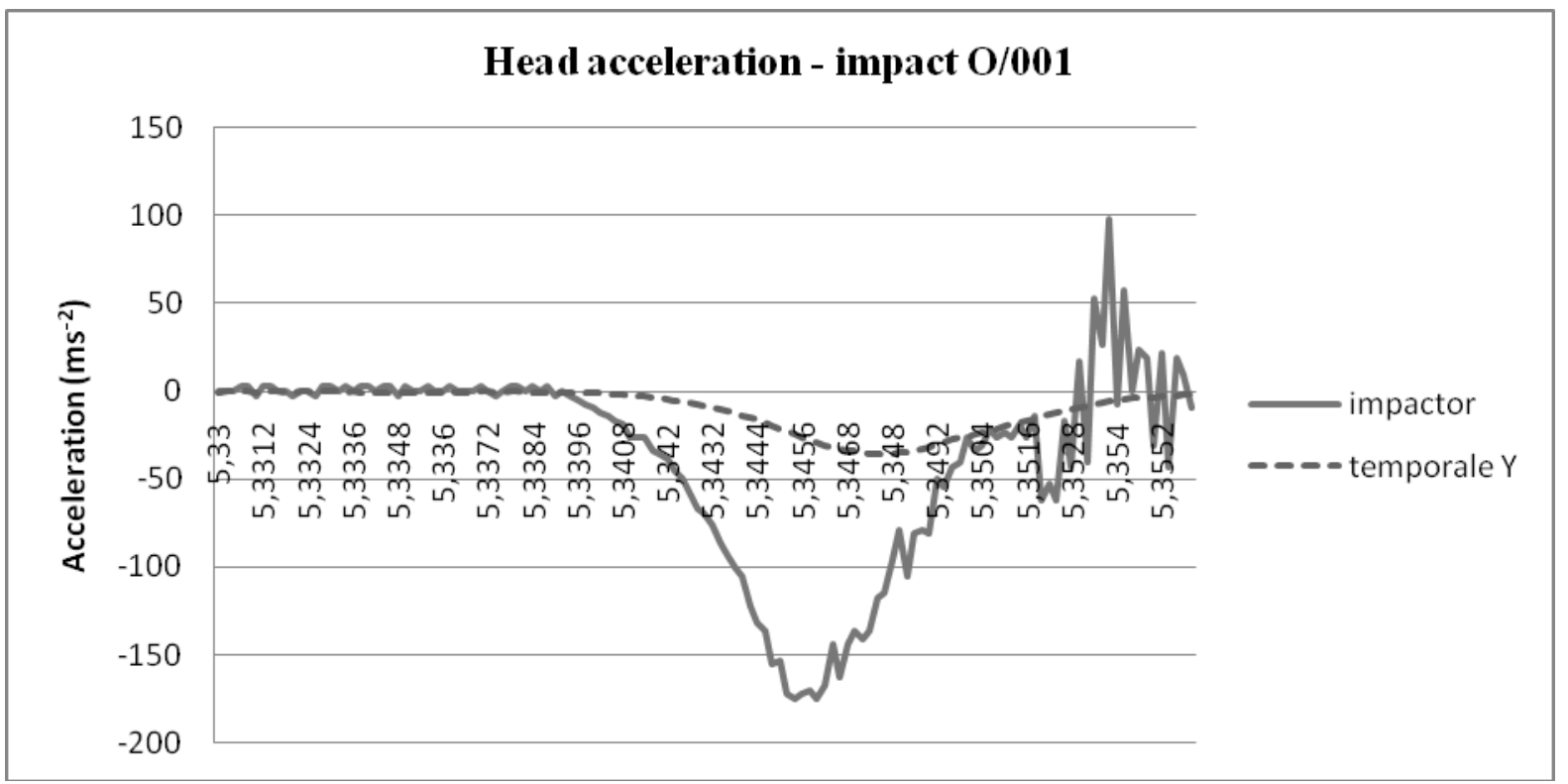

Figure 2: Head acceleration - impact $\mathrm{O} / 001$.

As can be observed with the figurine, shortly after the impact when the impactor's deceleration is still increasing the head is compressed in the anterodorsal direction and consequently expands along the $\mathrm{Z}$ axis. This ends at the moment when the impactor loses contact with the head, returns slightly and begins to oscillate. At this moment the acceleration is significantly increased along the $\mathrm{X}$ and $\mathrm{Y}$ axes. The $\mathrm{X}$ axis acceleration is caused mostly by a circular head movement around the rotation axis in the joint connection between the head and neck (Figure 3).

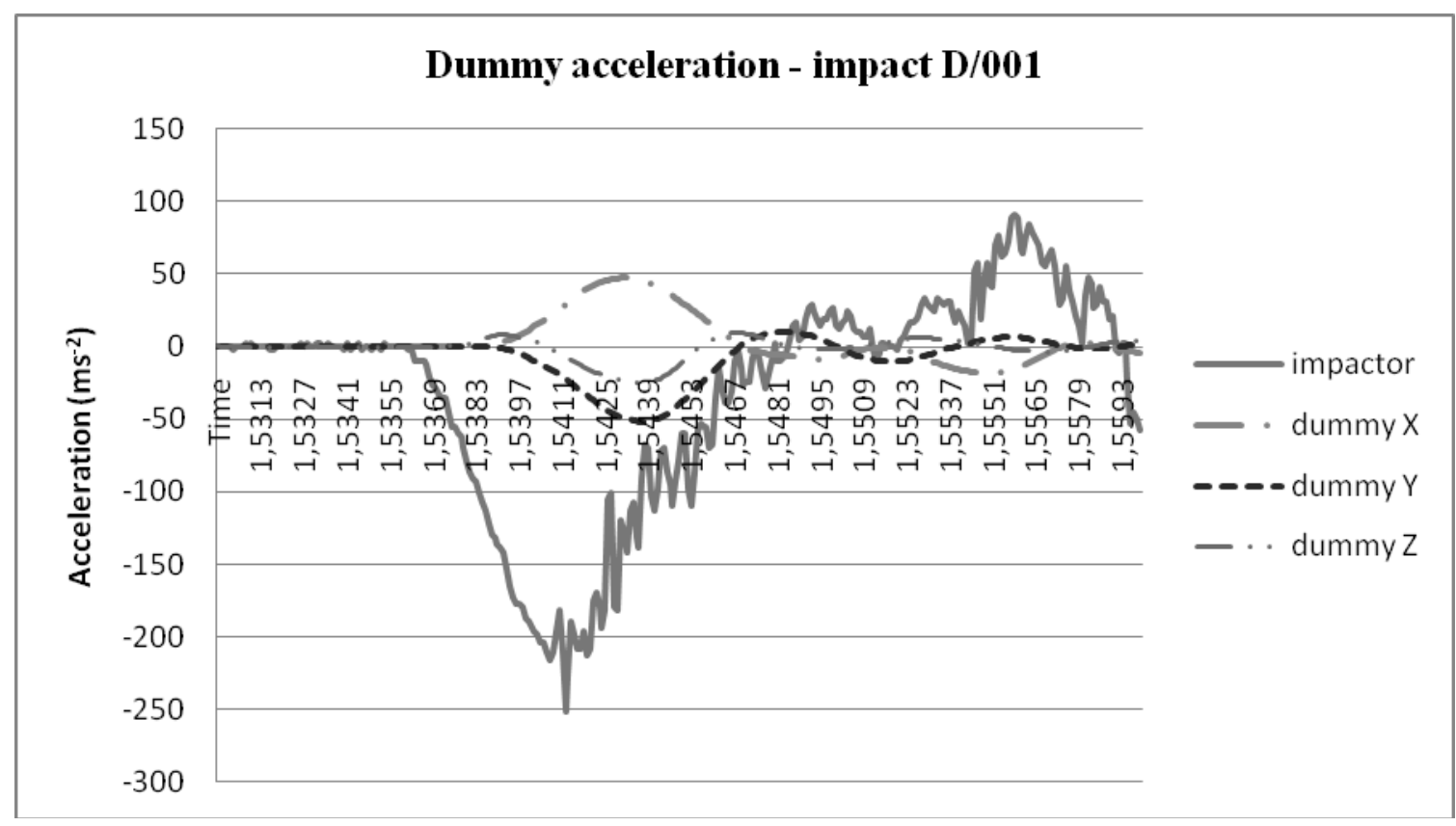

Figure 3: Dummy acceleration - impact D/001. 
The head's movement after the impact is defined as damped oscillation. Environment resistance can be considered equal to the speed value. It is evident that the inhibition is much stronger with a "live" head than with the figurine's. The figurine's head oscillates around the medium value with a larger amplitude, much like an oscilloscope (Figure 4).

This is due to the figurine's construction where the head-neck joint is implemented as an elastic connection without an inhibitor. This fact is important for the evaluation of HIC for the figurine.

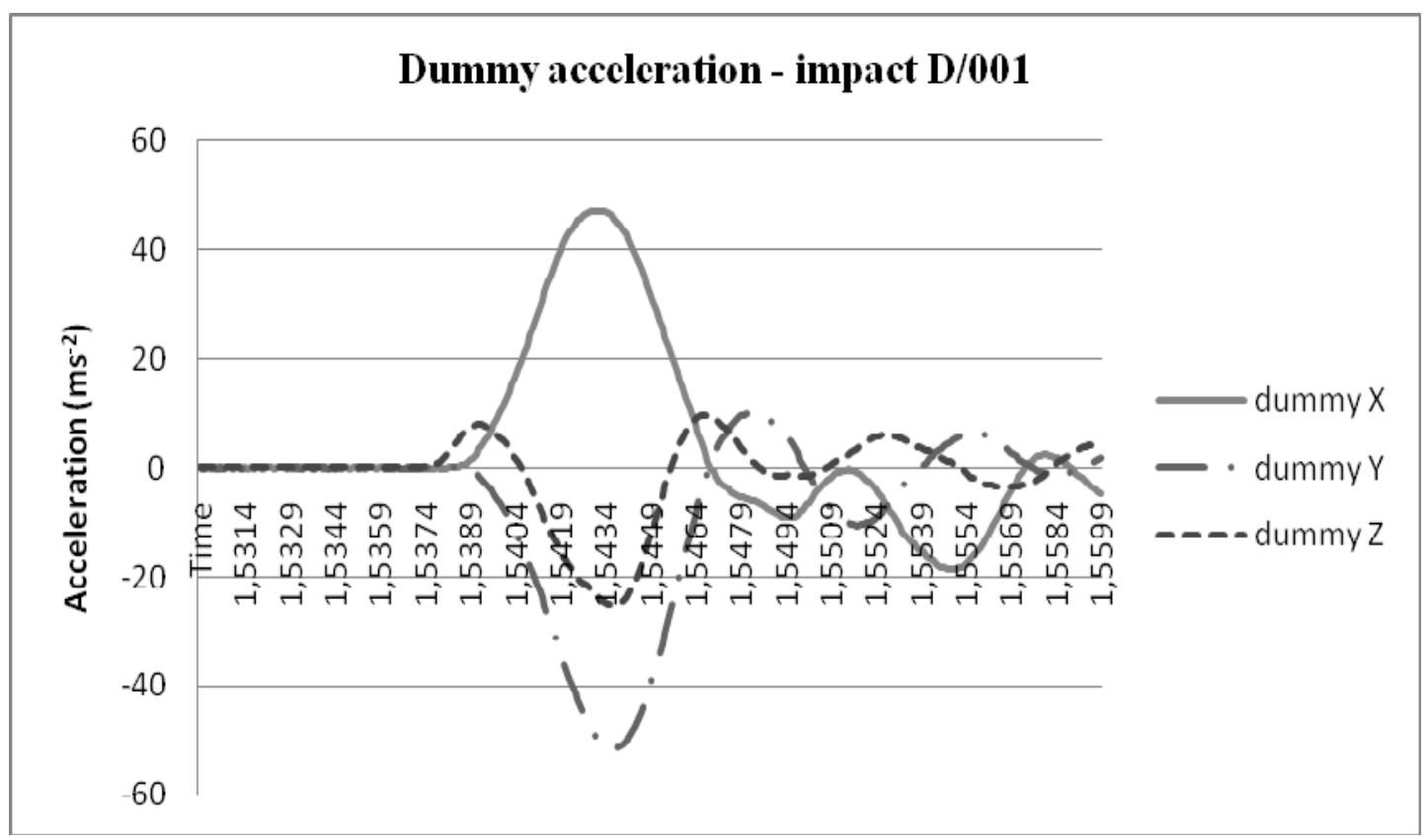

Figure 4: Dummy acceleration - impact D/001.

We will now concentrate on the increase in the "live" head acceleration depending on speed and strength of the impact (Figure 5,6). A little displacement of the pendulum (measurements 001 and 004) resulted in a slow impact of the order of $10 \mathrm{~ms}$ with a regular acceleration increase and decrease. A medium displacement (002 and 005) accelerated both the increase and decrease of the acceleration to approx. $8 \mathrm{~ms}$, while the inhibition is still smooth because of the inhibited aperiodic oscillation $b>\omega_{0}$, where $b$ is an inhibition constant and $\omega_{0}$ is a radial frequency of the oscillation itself. For the largest displacement (003 and 006) the time was shortened to approx. $6 \mathrm{~ms}$ and another wave in the inhibition was also noticed, as well as a slight short increase in the acceleration during deceleration. In this case the inhibition constant is lower than that of the radial frequency and of the oscillation $b<\omega_{0}$.

The impact was thus faster than the muscular activation (Horst, 2002). Similar plot shapes were reached for both probands with the only difference being for proband $\mathrm{O}$, with the weight increased on the impactor, which meant a stronger impact, and an increased time to the maximum acceleration value, which was more significantly decreased. 


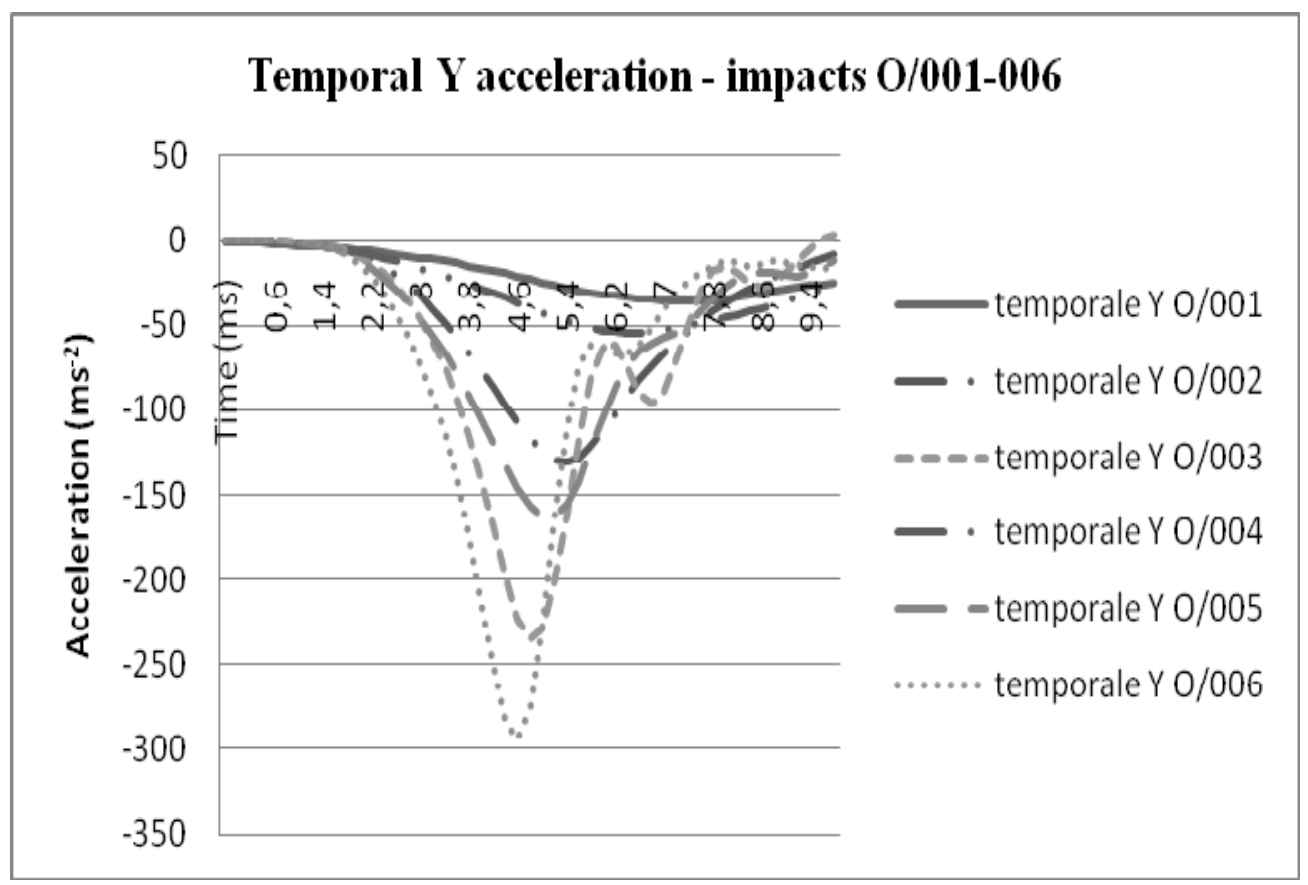

Figure 5 : Temporal Y acceleration - impacts 0/001-006.

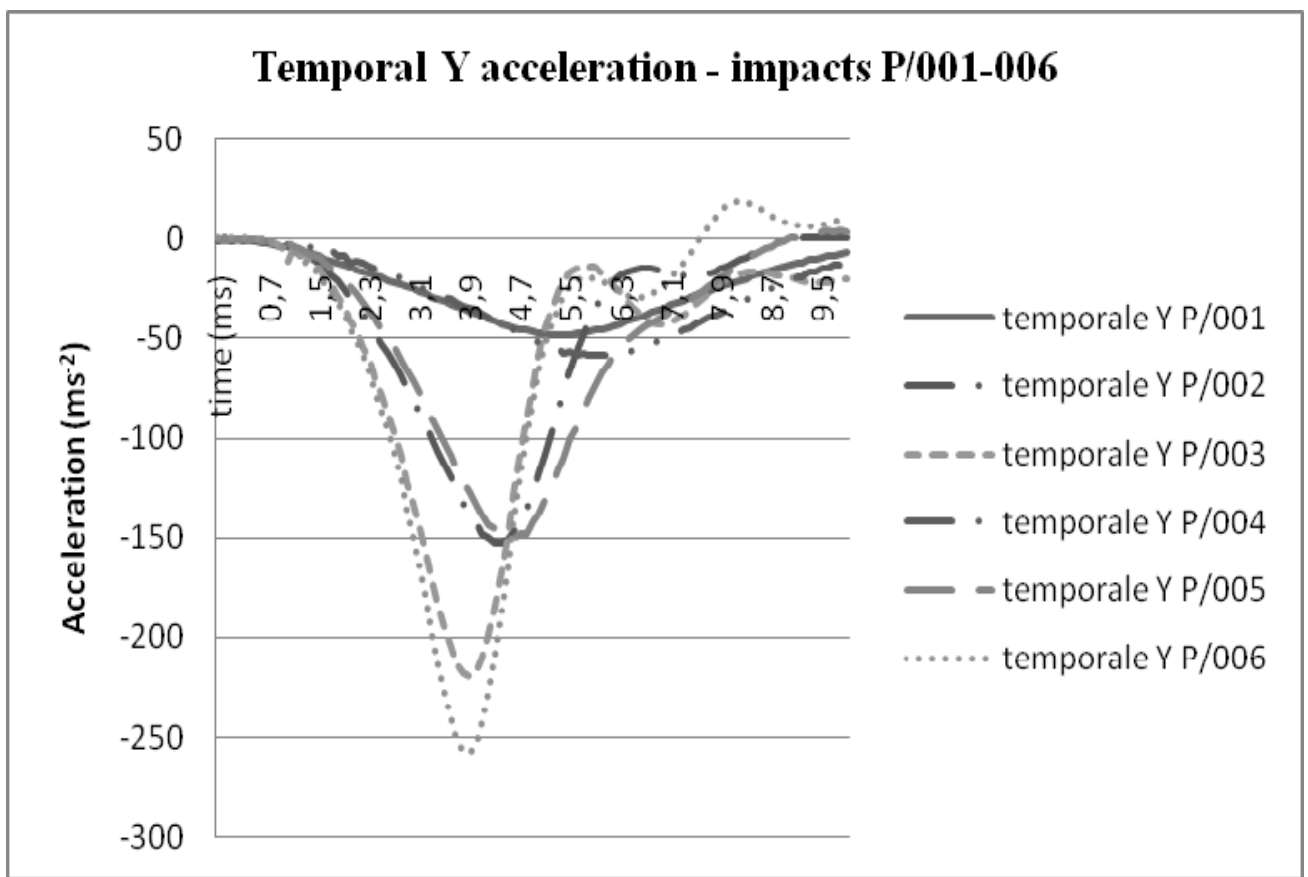

Figure 6: Temporal $\mathrm{Y}$ acceleration - impacts P/001-006.

No decrease in impact time depending on the impact strength could be seen for the figurine (Figure 7), only the maximum value of the acceleration increased and, as was mentioned, no significant inhibition $b<<\omega_{0}$ occurred. 


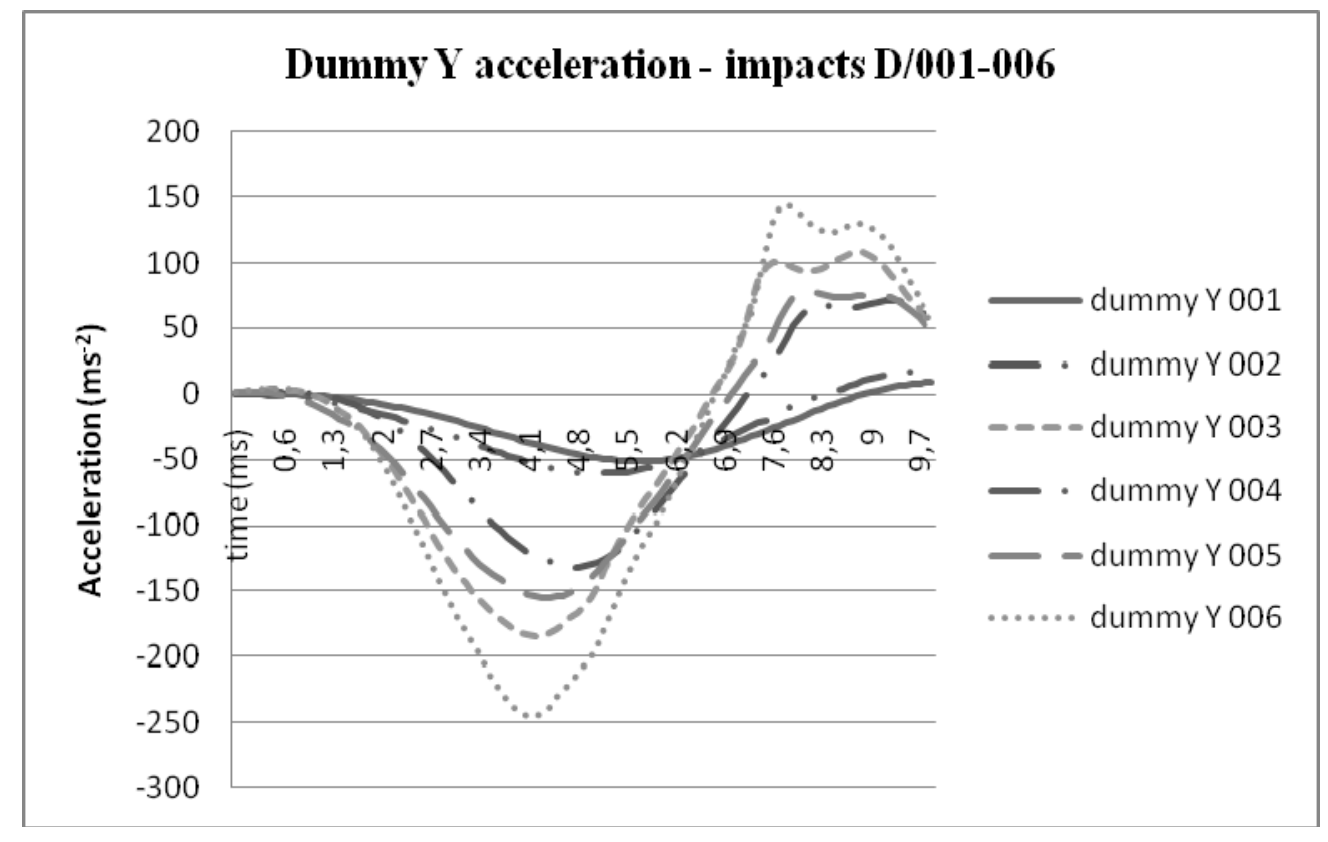

Figure 7: Dummy Y acceleration - impacts D/001-006.

In the next part we will compare "live" heads and a figurine head. With equal starting conditions the strength and course of the head acceleration are equal for both the figurine and "P" proband, while the "O" proband differs in every measurement mostly relating to the speed of increase and decrease of the acceleration (Figure 8-13). Both curves are much steeper. This may be caused by the rigidity of the skull, which is less elastic during the impact, but this is less likely than the different speed and efficiency of the neck muscles intervening. Proband $\mathrm{O}$ may be instinctively faster at resisting the impact using a significant involvement of neck muscles and thus making the impact seem harder and the response faster. However, according to the shock theory and the impact time this should have no particular influence either. The most likely explanation seems to be fastening the neck muscles resulting in a slightly different position of the cervical spine and the head, which was consequently loaded not only to bend, but also to buckle. This "resistance", however, looks counter-productive, as, from the subsequent evaluation of HIC, slightly higher values result than for proband $P$. The inhibition is for $\mathrm{O} / 003$ (Figure 10) and $\mathrm{O} / 006$ (Figure 13) also specified by more significant oscillations that could lead, in my opinion, to par contre-coup injury. On the other hand, some higher resistance to whiplash syndrome could be expected.

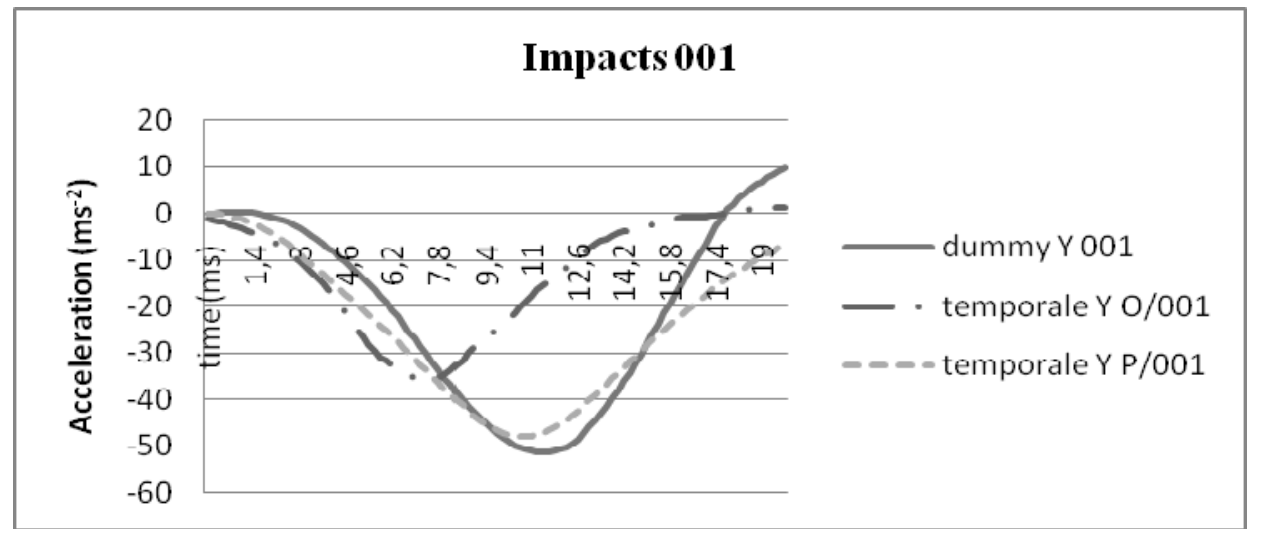

Figure 8: Acceleration - impacts 001. 


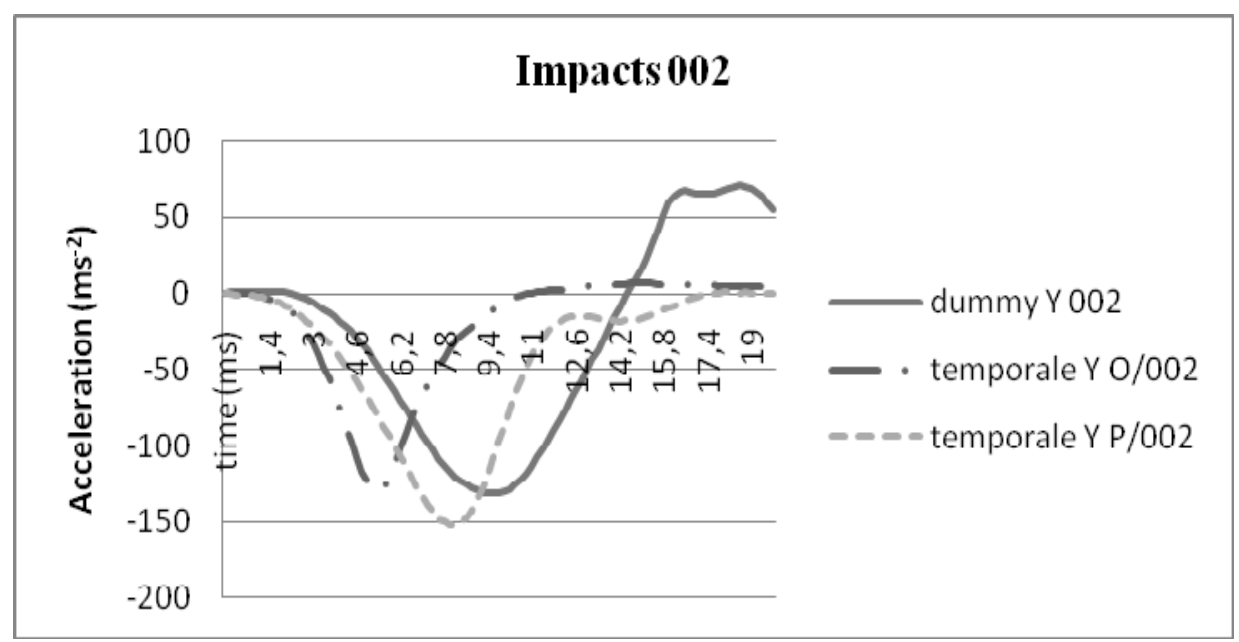

Figure 9: Acceleration - impacts 002.

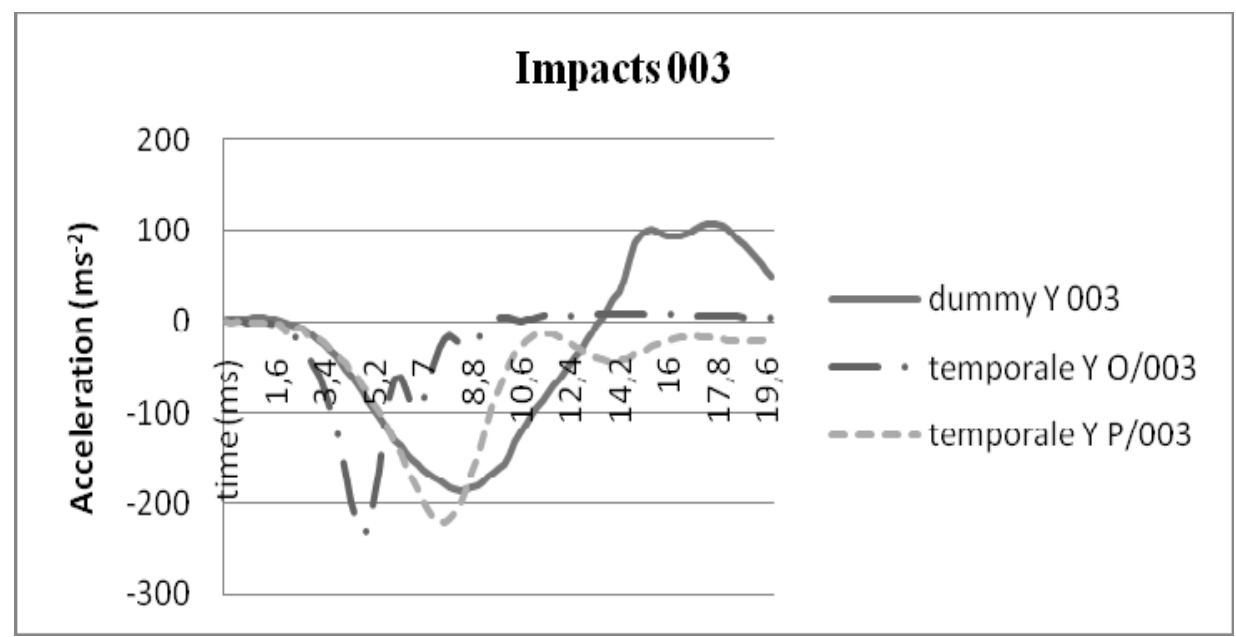

Figure 10: Acceleration - impacts 003.

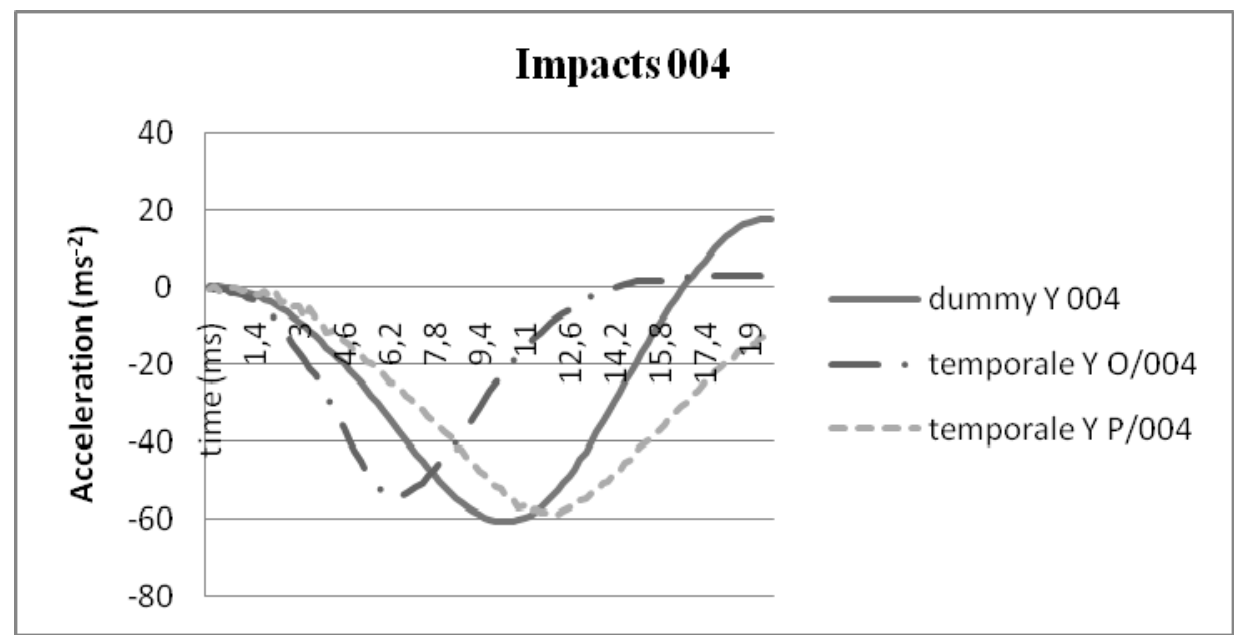

Figure 11: Acceleration - impacts 004. 


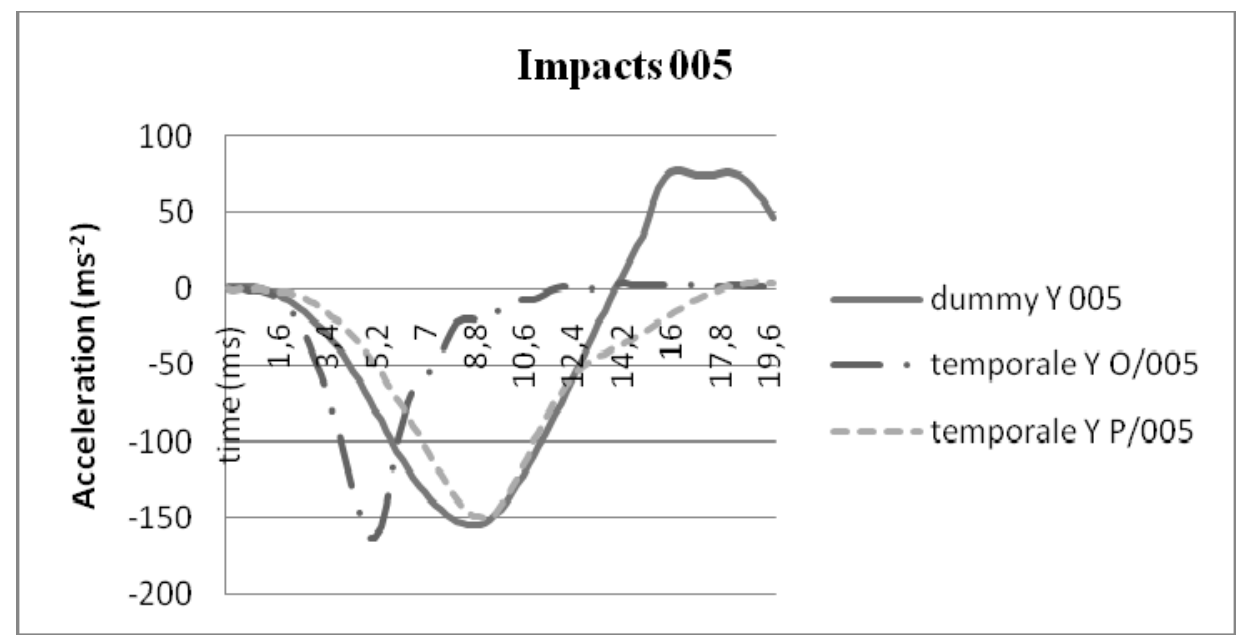

Figure 12: Acceleration - impacts 005.

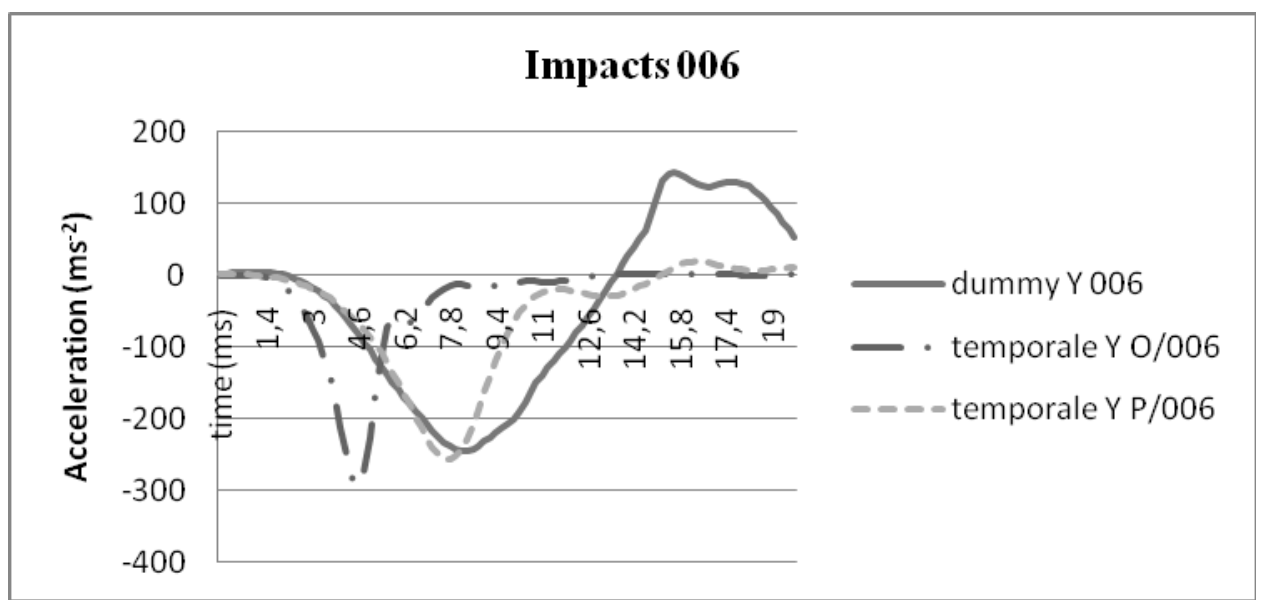

Figure 13: Acceleration - impacts 006.

If we now convert the obtained values using the equation:

$$
H I C=\left\{\left(t_{2}-t_{1}\right)\left(\frac{1}{t_{2}-t_{12}} \int_{t_{12}}^{t_{21}} a(t) d t\right)^{2,8}\right\}_{\max }
$$

and choose $15 \mathrm{~ms}$ as a time interval, considering the impact to be rigid, we can compare the risks of head injury for the test subjects and the figurine.

We can see similar values resulting for both probands (Table 2), even if they are slightly higher for $\mathrm{O}$ proband, which is caused by a faster acceleration increase as described above. For the figurine much higher values were attained, though. In the case of impact D/006 if the HIC value had been so high for a living person, it would have been exposed to a load causing lethal injuries. This is caused by a lack of inhibition for the figurine head compared to a "living" one as described above, and therefore its acceleration switches to opposite values instantly after the primary increase. Evaluating HIC for a shorted timespan and considering 
only the primary acceleration peak seems to be an appropriate solution. The HIC is then comparable to probands (Table 2, Figure 14, 15).

Table 2: Head Injury Criterion.

\begin{tabular}{|c|c|c|c|c|}
\hline HIC & $\begin{array}{c}\text { Tested } \\
\text { O }\end{array}$ & $\begin{array}{c}\text { Tested } \\
\mathrm{P}\end{array}$ & Dummy & $\begin{array}{c}\text { Dummy - } \\
\text { primary peak }\end{array}$ \\
\hline$/ 001$ & 18,7 & 17,5 & 18,9 & 12,0 \\
\hline$/ 002$ & 97,3 & 72,8 & 304,6 & 65,4 \\
\hline$/ 003$ & 188,1 & 176,7 & 707,9 & 134,2 \\
\hline$/ 004$ & 36,2 & 27,3 & 36,3 & 17,8 \\
\hline$/ 005$ & 127,7 & 110,2 & 446,5 & 109,6 \\
\hline$/ 006$ & 215,4 & 185,1 & 1428,2 & 256,8 \\
\hline
\end{tabular}

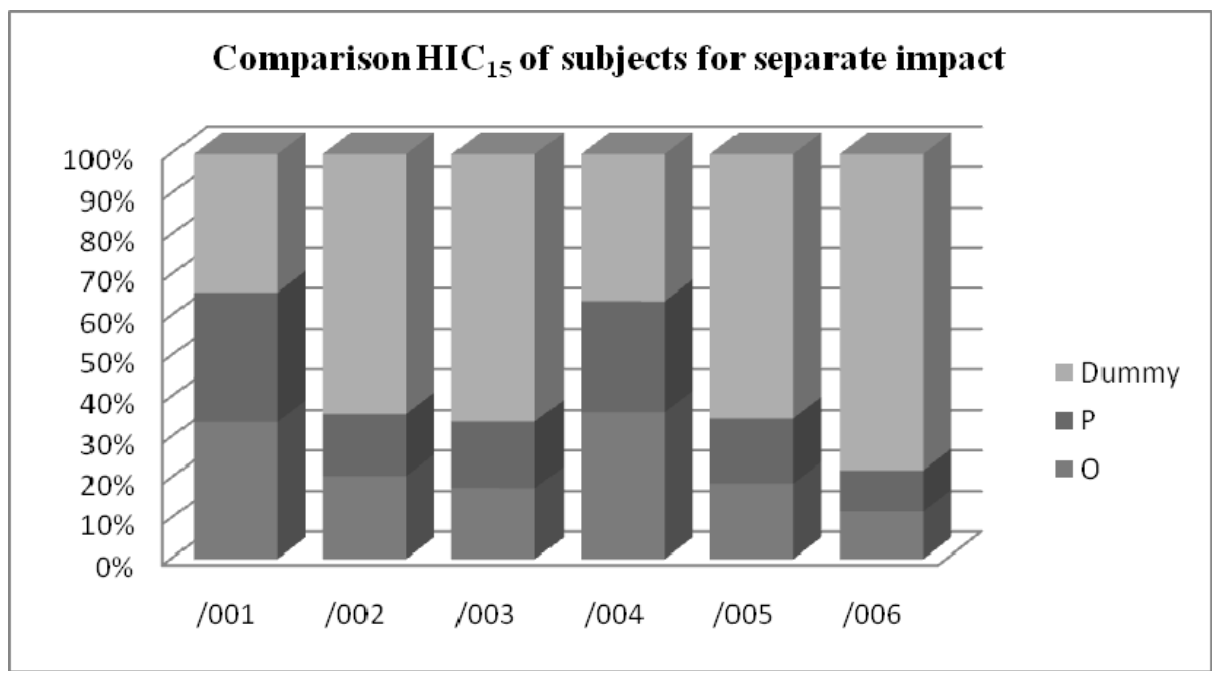

Figure 14: Comparison $\mathrm{HIC}_{15}$ of subjects for separate impact.

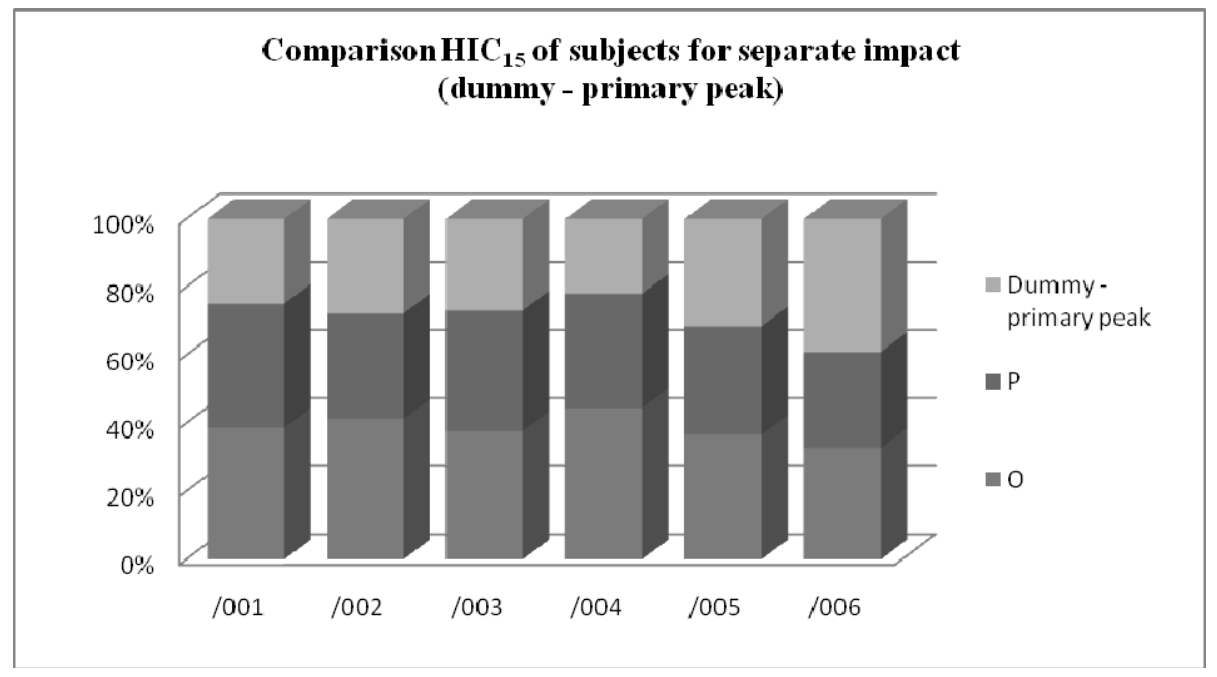

Figure 15: Comparison $\mathrm{HIC}_{15}$ of subjects for separate impact - dummy - primary peak. 


\section{CONCLUSION}

Only $\mathrm{Y}$ axis acceleration was detected on probands during the experiment (i.e., in the direction of the impact). Regarding the resulting acceleration to be:

$$
\bar{a}=\sqrt{a_{x}^{2}+a_{y}^{2}+a_{z}^{2}}
$$

and considering that $a_{x}<<a_{y}$ and $a_{z}<<a_{y}$, we may presume that $\bar{a}=\sqrt{a_{y}^{2}}$.

If we take into account that EES (Energy Equivalent Speed) comes up to the strongest of tested impacts, than the highest measured HIC for a proband was 215, which corresponds to EES speed $<21 \mathrm{~km} / \mathrm{h}$ (Fanta, 2009). According to the correlation of HIC and AIS we may presume a $95 \%$ probability of AIS 0 .

The experiment confirmed the validity of an HIC and AIS correlation for low speed and strength of impact (HIC values about 200). For higher HIC values it would be necessary to simulate the whole situation using simulation software. This will be accomplished in future projects.

For a figurine and a short, rigid impact it is advisable to evaluate using only the primary acceleration peak.

\section{ACKNOWLEDGEMENTS}

This project is supported by GAČR P 407/10/1624 and GAUK 111310.

\section{REFERENCES}

Brands, Davy W.A. 2002. Predicting brain mechanics during closed head impact : numerical and constitutive. Eindhoven: Technische Universiteit Eindhoven, 2002. ISBN 90-3862713-0.

Fanta, Ondřej. 2009. Biomechanická odpověd’ na impaktní zátěž crania. Diplomová práce. Praha : UK FTVS, 2009. Vedoucí diplomové práce Karel Jelen.

Horst, van der Marike J. 2002. Human Head Neck Response in Frontal, Lateral and Rear End Impact Loading. Eindhoven : Universiteitsdrukkerij TU Eindhoven, 2002. ISBN 90386-2843-9.

Juráň, Vilém, Smrčka, Martin and Smrčka, Vladimír. 2001. Poranění mozku. Lékařská fakulta, Masarykova Univerzita. [Online] Leden 5, 2001. [Cited: Listopad 10, 2007.] http://www.med.muni.cz/Traumatologie/Neurochirurgie/Medici_traum.htm.

Kovanda, Jan and Šatochin, Vladimír. 2000. Pasivní bezpečnost vozidel. Praha : ČVUT, 2000. ISBN 80-01- 02235-8. 
Ommaya, Ayub K., Thibault, Lawrence and Bandak, Faris A. 1994. Mechanisms of impact head injury. Elsevier Science Ltd. 1994, Vol. 4, 15, pp. 535-560.

Ran, A., Koch, M. and Mellander, H. 1984. Fitting Injury versus Exposure Data into a Risk Function. Bron: Proceedings of the International IRCOBI Conference on the Biomechanics of Impact held at Delft, The Netherlands, 1984.

Sychra, Pavel. 1993. Poranění osob upoutaných bezpečnostními pásy. Soudní inženýrství 3/4, 1993, pp. 38-45.

Tarriere, C. 1981. Head and Neck Injury Criteria - a Consensus Workshop. Washington D.C. : U.S. Dept. of Transport, NHTSA, 1981. pp. 218-228. 